\title{
Transfer Model and Decision Support System of Smart Microgrids Multiple Distributed Power
}

\author{
Zhu Jiayi, Zhou Kaihe, Dai Yunfei, Fang, Lyu Caibo, Yunhui* \\ Ningbo power Supply Company of State network Zhejiang Electric Power \\ Corporation, Ningbo 315007 \\ *Address correspondence to Fang Yunhui, email: fangyunhuil@163.com
}

\begin{abstract}
This work aims to study a variety of distributed power access based on the theory of operation microgrid control. It provided a theoretical reference and reference for the development of micro-engineering application grid technology. In this paper, the risk characteristics of grid operations management side under the background of the smart grid, from project investment, load forecasting, renewable energy power purchase access, economic dispatch, information security, and constructed investment project set risk transfer model, load forecasting risk transfer model, considering the economic dispatch model smart grid element of risk transfer. It takes into account price and load uncertainties purchase risk transfer element optimization model, smart grid information security risk assessment element transfer model to study the dynamics of the smart grid from a risk point of view under the grid-side operational risk management.
\end{abstract}

Keywords: Distributed power; microgrid operation control; mode change

\section{Introduction}

With the continuous expansion of the size of the grid, the traditional centralized power generation and construction of long-distance transmission grid pattern showing an increasing number of limitations. On the other hand, with the depletion of conventional fossil energy sources, clean and efficient renewable energy technology has been widespread concern. To meet the challenges, many countries have put forward a smart grid construction as the core of future grid development strategy. Micro-grid can integrate a large number of new distributed energy generation, will help solve the various problems encountered in large power grids, it is an important part of the future smart grid distribution network. Research on control method under various operating conditions of access to distributed power microgrid has important theoretical and practical significance.

In order to ensure energy security, improve energy structure and address the needs of the development of the social environment, many countries in accordance with national conditions and characteristics of energy power industry, have developed a distinctive smart grid construction as the core of future grid development strategy. Compared with the traditional grid pattern, smart grid has many advantages: First, the smart grid can fully meet the load demand for the rapid growth in the economy while increasing power supply to ensure power supply security and reliability. Second, the smart grid can fully access renewable energy to improve the energy structure, to meet the electricity needs of the user diversity. In addition, the smart grid can contribute also to the electricity market, and promote optimal allocation of resources and improve the operation and management level of power enterprises. In summary, the smart grid is the future trend of the grid.

This work aims to study based on the theory of operation of microgrid control a variety of distributed power access, and to provide a theoretical reference and reference for the development of micro-engineering application grid technology. This paper considers a variety of commonly used in micro-grid distributed power, in-depth study based on 
various control methods and operating distributed power microgrid control strategy and operation mode conversion method, and on this basis, the study based on an inverterbased Distribution power control of microgrid power quality management. In this paper, the risk characteristics of grid operations management side under the background of the smart grid, from project investment, load forecasting, renewable energy power purchase access, economic dispatch, information security, were constructed investment project set risk transfer model, load forecasting risk transfer model, considering the economic dispatch model smart grid element of risk transfer, taking into account price and load uncertainties purchase risk transfer element optimization model and smart grid information security risk assessment element transfer model to study the dynamics of the smart grid from a risk point of view under the grid-side operational risk management.

\section{Electricity Risk Element Transmission Theory and Distributed Power Access}

\subsection{Electricity Risk Element Transmission Theory}

Electric power enterprise risk element transmission theory research question as to cause some changes in the risk of changes in other domains of risk domains, that is the risk for some changes in the study of causes audiences (such as electricity business management objectives) the risk of changes . In general, the record for the domain:

$$
U=\left\{x_{1}, x_{2}, \cdots, x_{n}\right\}
$$

Where: Xi represents risk study, is an uncertain value.

Where $\mathrm{x}$ is the risk element, $\mathrm{S}$ is non-empty (Cantor set), $\mathrm{S}$ '<z. $\mathrm{S}, \mathrm{U}$ is ".x in s", A is "X in s'", then A is called gray information. make:

$$
\bar{\mu}(x)=\left\{\begin{array}{l}
1, x \in S^{\prime} \\
0, x \notin S^{\prime} \text { and } \quad x \in S \quad \underline{\mu}(x) \equiv 0, x \in S
\end{array}\right.
$$

Such an outcome measure that may arise and the possibility of the emergence of some kind of comprehensive risk described as uncertain conditions. The most common representation is generally possible results with the possibility of the product of the way that the expectations. The measure is the most risk assessment applications mainstream risk measurement methods, the power companies are relatively more common.

Referring to the definition of risk and risk elements, measure risk element comprises two categories: First, the traditional measurement method, the second is an extension of the measure. The traditional measurement methods mainly based on probability theory and mathematical statistics, four results from uncertainty under conditions of possibility, combined with the possibility of the results, and other differences to measure the risk element; the extended measure random element of risk, fuzzy risk element, gray risks yuan, unascertained risk element to measure. Different cell types have different risk characteristics of its representation, practical situations are not the same was shown in Table 1.

Table 1. The Representation of Quantitative Risk Element

\begin{tabular}{l|l|l|l}
\hline $\begin{array}{l}\text { Risk } \\
\text { element }\end{array}$ & $\begin{array}{l}\text { Representation } \\
\text { method }\end{array}$ & Use situation & Characteristic \\
\hline $\begin{array}{l}\text { Random } \\
\text { risk element }\end{array}$ & $\begin{array}{l}\text { Probability } \\
\text { method }\end{array}$ & $\begin{array}{l}\text { It can be reasonably } \\
\text { assumed to be some } \\
\text { kind of probability } \\
\text { distribution }\end{array}$ & $\begin{array}{l}\text { Objectivity is strong, there } \\
\text { are plenty of prior data or } \\
\text { theoretical support. }\end{array}$ \\
\hline $\begin{array}{l}\text { Fuzzy risk } \\
\text { element }\end{array}$ & Fuzzy way & $\begin{array}{l}\text { The lack of a priori } \\
\text { data support, the }\end{array}$ & $\begin{array}{l}\text { Subjectivity is strong, } \\
\text { practical, the required a }\end{array}$ \\
\hline
\end{tabular}




\begin{tabular}{l|l|l|l}
\hline & & $\begin{array}{l}\text { uncertainty of the } \\
\text { measurement requires } \\
\text { a person's subjective } \\
\text { judgment is given }\end{array}$ & $\begin{array}{l}\text { priori data conditions are } \\
\text { limited. }\end{array}$ \\
\hline $\begin{array}{l}\text { Gray risk } \\
\text { element }\end{array}$ & Grey set & $\begin{array}{l}\text { Part information } \\
\text { known, part } \\
\text { information unknown, } \\
\text { measured by grey } \\
\text { subset interval }\end{array}$ & $\begin{array}{l}\text { Has "the same, different, } \\
\text { non -" three kinds of } \\
\text { meanings, simultaneously } \\
\text { contains the partial known, } \\
\text { partly unknown meaning }\end{array}$ \\
\hline $\begin{array}{l}\text { Uncertain } \\
\text { risk element }\end{array}$ & $\begin{array}{l}\text { Uncertainty be measured by } \\
\text { mathematics } \\
\text { the unascertained } \\
\text { number }\end{array}$ & $\begin{array}{l}\text { Understanding of purely } \\
\text { subjective, uncertainty, } \\
\text { randomness and fuzziness } \\
\text { neither }\end{array}$ \\
\hline
\end{tabular}

This measure will result in a measure of risk that may arise under uncertainty based. For example, in Comprehensive Evaluation of electricity companies, despite the theoretical risk recognition in the evaluation of the relative importance of uncertainty, we must also consider the consequences of the degree of probability of occurrence and the corresponding two aspects of information, but in practice it is only emphasized the serious consequences degree, do not focus on their likelihood. That emphasis on results this definition, the corresponding risk monism domain:

$$
U=\left\{c_{1}, c_{2}, \cdots, c_{n}\right\}
$$

This measurement will be described as a difference in risk between the various outcomes, the results of the risk level and the size of the difference between closely related, generally using some distance (Euclidean distance, Mahalanobis distance, etc.) to act as a metric, which the most common manifestations of variance. Differences either by itself or the result of the probability of occurrence for that can also be used to describe both the overall representation.

\subsection{Distributed Power Access}

Constant power (PQ) to control active power inverter output and reactive power control target, commonly used in distributed power connector inverter control micro power grid running. Suppose grid connected inverter output voltage three-phase fundamental M, by the power grid voltage clamp, $u$ is the voltage amplitude of $U$ was converted Park:

$$
\left[\begin{array}{l}
u_{d} \\
u_{q}
\end{array}\right]=T_{a b c->d q}\left[\begin{array}{l}
u_{a} \\
u_{b} \\
u_{c}
\end{array}\right]=\left[\begin{array}{c}
U_{m} \\
0
\end{array}\right]
$$

Three-phase voltage three-phase static abc coordinate system is coupled, in the synchronous rotating dq coordinate system, d-axis component and 9-axis component of the solution can be implemented pro. When the inverter output voltage is determined by the grid voltage, equal to a constant $\mathrm{Um}, \mathrm{M},=0$. At this time, control of the inverter output power can be converted into a control current, active power output given by the iq, reactive power output given by the iq, enabling the inverter output active and reactive power decoupling control. PQ inverter control reference current can be determined by the following formula: 


$$
\begin{aligned}
& i_{\text {dref }}=P_{r e f} / u_{d} \\
& i_{\text {dref }}=-Q_{\text {ref }} / u_{d}
\end{aligned}
$$

Wherein, $\mathrm{P}$ and $\mathrm{Q}$ are active and reactive power reference value output.

Principle PQ control block diagram was shown in Figure 2, preclude the use of outer loop power control and closed-loop current control dual control structure of the inner ring.

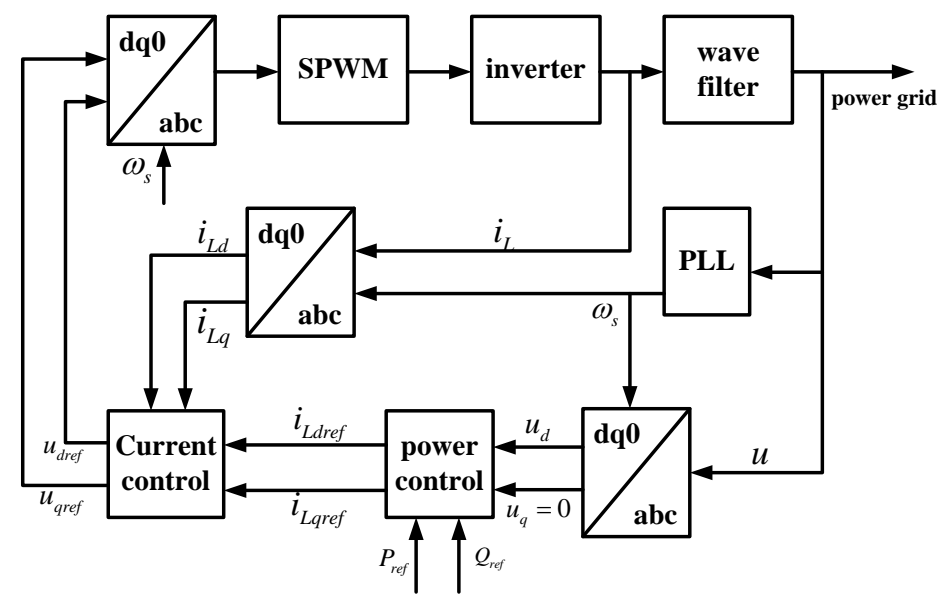

Figure 2. $P Q$ Control Block Diagram

Under the smart grid environment for renewable energy generation involved in the management side of the operation to wind power, for example, to build a wind power operations management and risk transfer model element wind - fire joint operational risk transfer model element corresponding quantitative risk analysis. On the one hand, participation in power generation side of the operation and management of wind power alone operation and management process, and to seize the wind power electricity price of wind power grid power two main lines were constructed element of risk transfer model for quantitative analysis. Wind power electricity price risk element transfer model considers the annual power output, system cost, and policy risk element on wind power feed-in tariff; wind power grid electricity risk element transfer model considers wind power risk element and the grid capacity to accept risk element on the Internet charge influences.

\section{Risk Transfer Element Model under Smart Grid Environment}

\subsection{Risk Transfer Element Model}

Development of smart grid and renewable energy technology is increasingly becoming an important way to solve the current energy crisis, while construction of smart grid also contributed to the large-scale renewable energy generation and safety nets. Renewable energy sources include solar, wind, hydropower, biomass, hydrogen, wave energy, which is sustainable and environmentally friendly. With the energy crisis and environmental pollution intensifies, the urgent need for the introduction of low-emission, low-pollution energy in order to reduce pressure on the environment, and renewable energy sources are widely distributed, with concurrency may be utilized, its short-term self-recovery capabilities to ensure that it can continue production more power. 
However, the characteristics and power generation and renewable energy generators are available with traditional thermal power generating units have a fundamental difference, environmental factors affected by large scale renewable energy grid, there are some significant operational management issues. In order to enhance the smart grid construction level and ensure the security and stability operations, research under the new environment of smart grid power generation side operational risk management is of great significance.

Intermittent renewable energy generation, load forecasting uncertainty, the uncertainty of tariff and thermal power fuel price uncertainty, bringing wind - fire joint operational risk management, so that the following conditions for this assessment modeling detailed analysis. Given the impact of the smart grid operation and management of power generation side it is mainly reflected in two main aspects, one of their own renewable energy operations management, renewable energy and other conventional energy cogeneration operation and management (Figure 3). Therefore, this paper for the generation side operational risk management under the smart grid environment from two aspects research, and build wind power operational risk management transfer element model, wind - fire risk element of joint operations management transfer model.

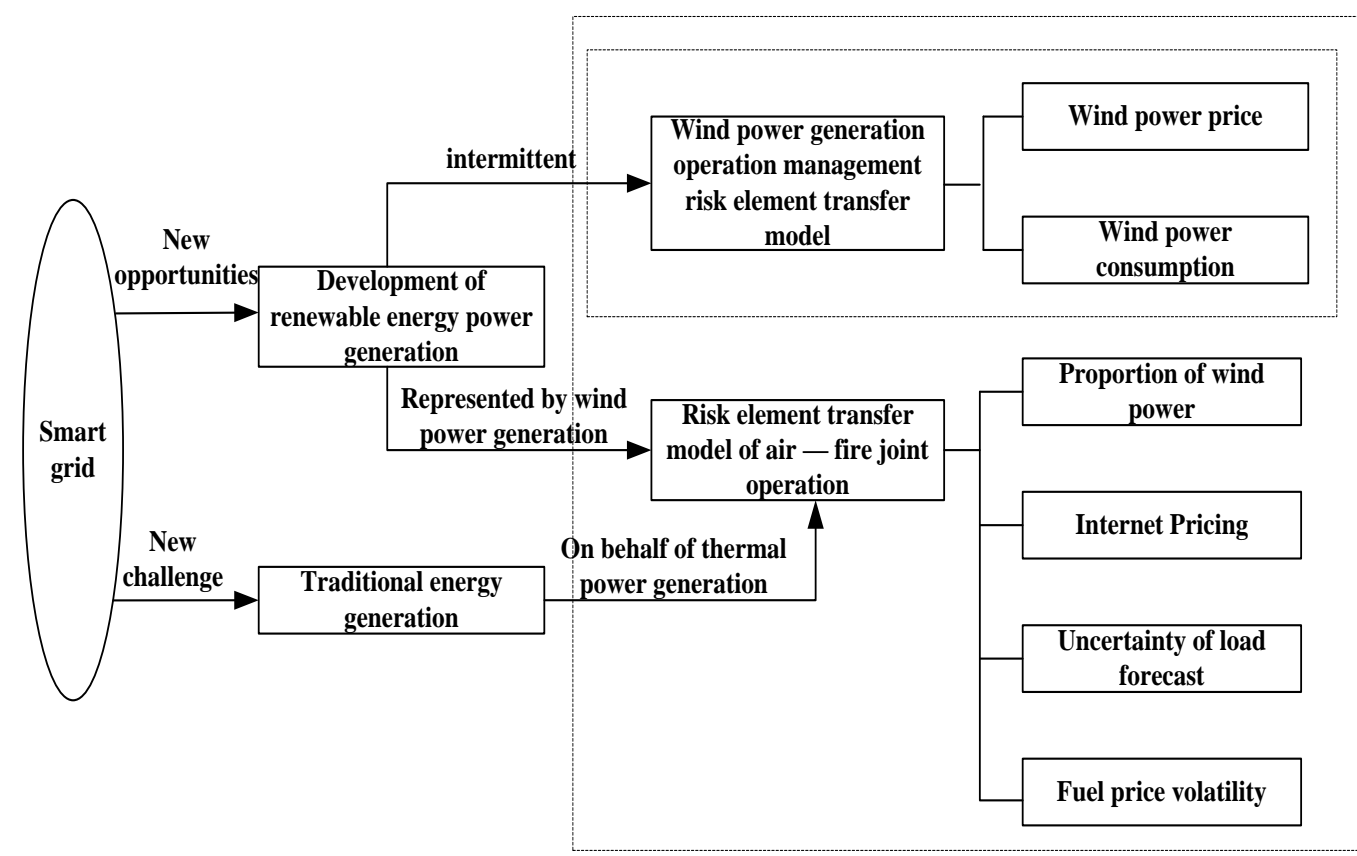

Figure 3. Power Side Operational Risk Management Transfer Structure
Element

In response to the deterioration of the global climate and improve energy efficiency, countries are beginning to make the power industry to explore the smart grid. The implementation of the smart grid as another reform of the electricity industry, the operators managed to bring a new round of the main challenges, particularly renewable energy generation to participate in operations management side and connected to the grid, power dispatch by the dispatch of electricity into load scheduling, the user side through the intelligent management of the grid operator involved in a two-way interactive system. Compared to conventional power systems, intelligent power grid of the electricity flow, information flow, capital flow and highly integrated, power systems has injected new vitality, but also to some extent increase the risk of various operations management body. 


\subsection{Modeling and Control of Solar Photovoltaic}

Photovoltaic cells is the foundation and core of solar photovoltaic power generation, which uses the photovoltaic effect produced when certain materials by blessing the sun light solar radiant energy into electrical energy, the equivalent circuit was shown in Figure 4. Iph is the photocurrent, Ipd diode junction current, $\mathrm{C}$ is the junction capacitance can be neglected in the analysis, $\mathrm{Rh}$ is the series resistance. According to the equivalent circuit model and diffusion theories can be obtained:

$$
I_{p v}=I_{p h}-I_{p v 0}\left\{\exp \left[\frac{q\left(V_{p v}+R_{s p v} I_{p v}\right)}{n k^{\prime} T^{\prime}}\right]-1\right\}-\frac{V_{p v}+I R_{s p v}}{R_{s h}}
$$

Wherein, Ipvo is the reverse saturation current, of the order of $10-1 \mathrm{~A}, \mathrm{q}$ is the electron charge 1.6C:, $\mathrm{n}$ 'is a diode factor, in the range of $1-5, \mathrm{k}$ ' is Boltzmann's constant $1.38 \mathrm{~J} / \mathrm{K}$, $\mathrm{T}$ 'is the absolute temperature. The formula for the photovoltaic cell voltage and current relationship equation, based on the basic principle of a photovoltaic cell expression obtained, is widely used in the theoretical analysis of the photovoltaic cell. Its appropriate simplified photovoltaic cell can be obtained simplified model to meet the actual needs of the project.

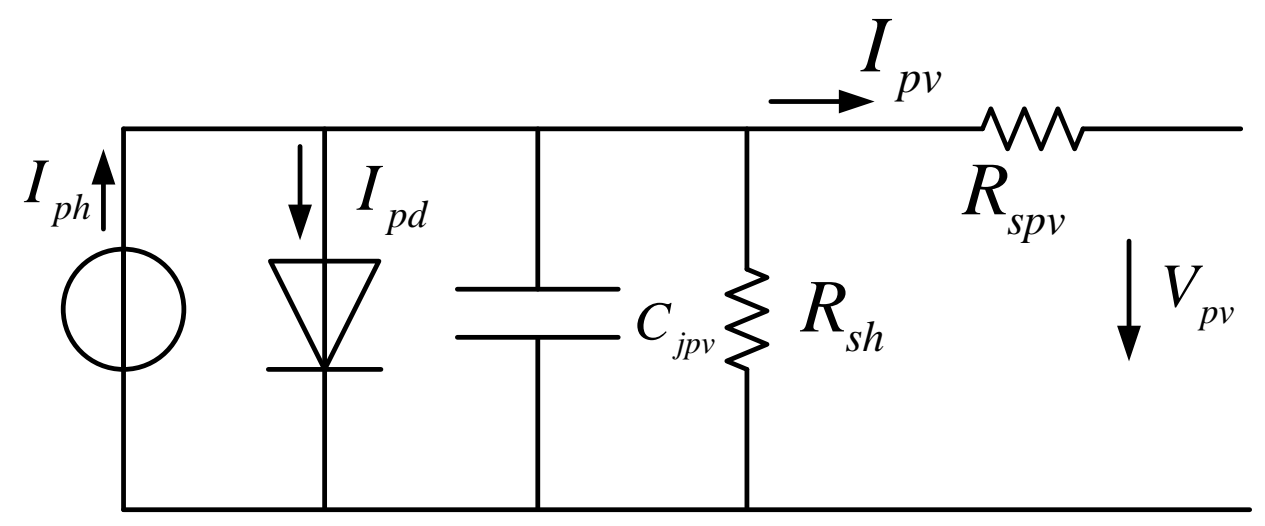

Figure 4. Photovoltaic Cell Equivalent Circuit

Draw the photovoltaic cell according to the I-V characteristic curve, as shown in Figure 5. Power port are short-circuit current and open circuit voltage of the photovoltaic cell. When the value of the load by increasing the resistance or direct voltage control assembly is increased from zero (short-circuit conditions), output power components also increased from zero. When the voltage reaches a certain value, the maximum power can be achieved, then when the voltage continues to increase, the maximum power point of the cross, and gradually reduced to zero, that voltage reaches the open circuit voltage corresponding to the maximum power point voltage is called the maximum power point voltage the point corresponding to the current is called the maximum power point current 4 , is called the power of the maximum power point based on nonlinear characteristics of photovoltaic cells, solar photovoltaic power generation is necessary to ensure that they are always run in the maximum power point. 


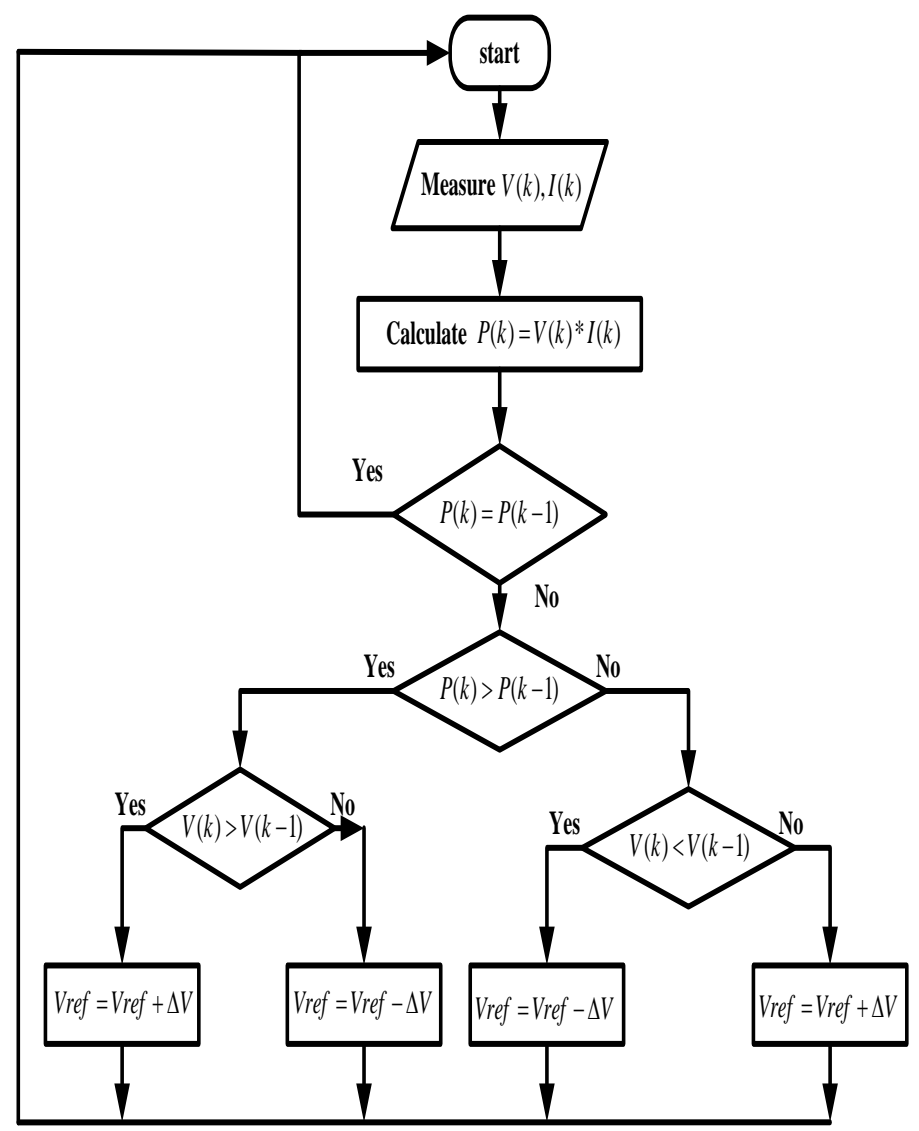

\section{Figure 5. The Photovoltaic Cell According to the I-V Characteristic Curve}

In different operation modes, micro-grid inverter control method has a big difference, while the operation mode is changed, the control method used also requires timely automatic adjustment Generally, there are three micro-grid structure composed of: Lord from the structure, and other structures and hierarchy. Control Strategy microgrid composed of different structures have taken a big difference, especially reflected in the island micro-grid operation mode. In this paper, research on microgrid different structures were put forward the corresponding micro-grid operation and grid control strategies and island operation mode switching control method.

\subsection{Simulation Analysis}

Figure 6 shows the first three charts are simulation results using unity power factor and sensitivity analysis methods DFIG reactive power control power and voltage. The same in both cases DFIG active power Pi, we have captured the largest wind energy. When unity power factor control DFIG reactive power output $01=0$, reactive power emitted when the sensitivity analysis with active control 仏 changes constantly adjust. 

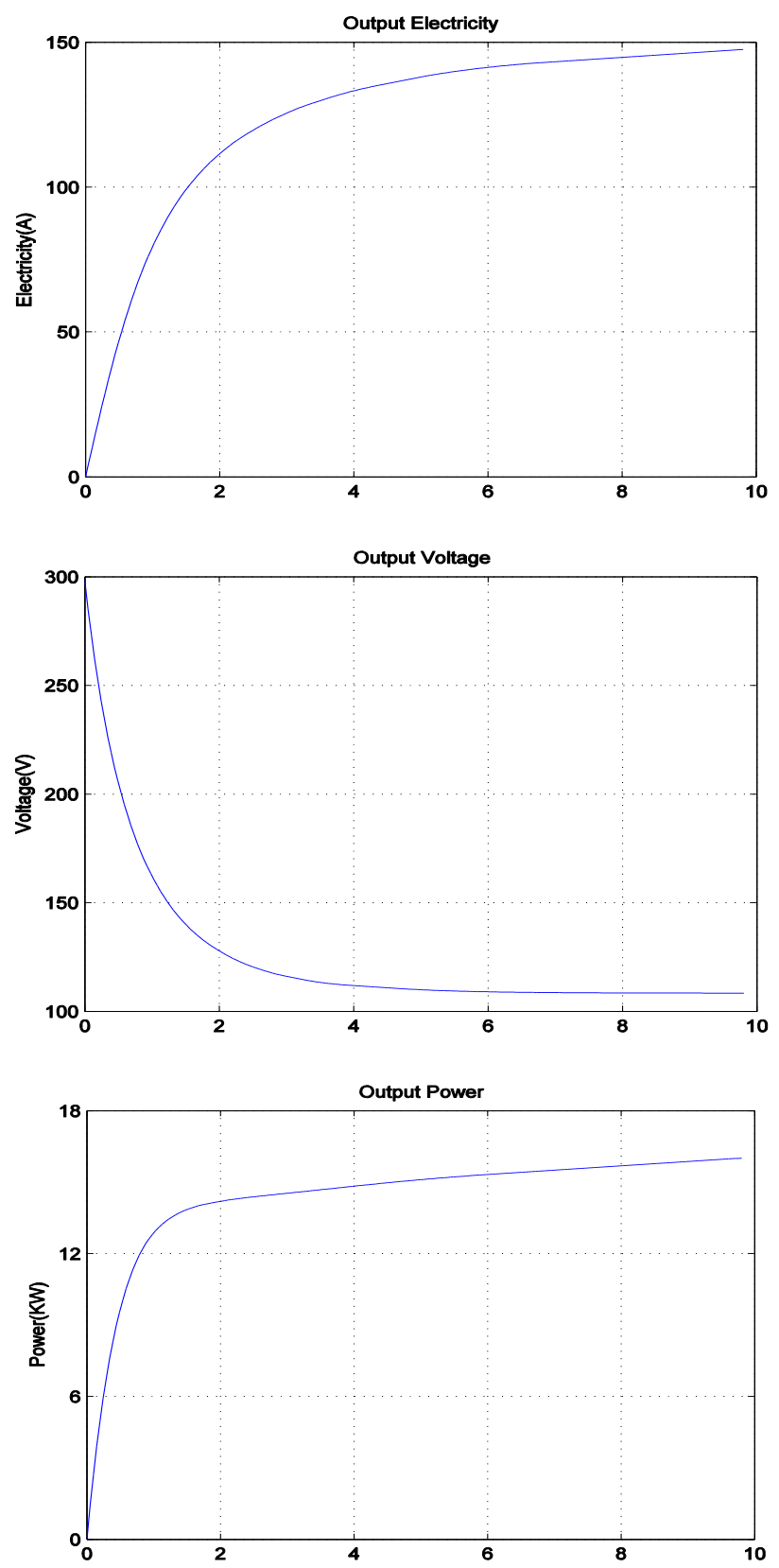

\section{Figure 6. The First Three Charts Simulation Results}

Qf and Qs represent reactive power when using the method of sensitivity analysis grid side converter and the stator side issue, as can be seen from Figure 01 priority shall be borne by the grid side converter, when the lack of grid side converter when the capacity responsible stator side. The fourth figure shows the comparison of two cases and network interface node voltage, the impact can be seen when using the unit power factor control voltage by DFIG active power changes have significant fluctuations, and the use of sensitivity analysis method for controlling the DFIG No after the reactive power voltage is improved.

Responsible for monitoring the main power microgrid that various changes in electrical quantities, - and be adjusted according to the actual operation. In addition, the main power supply is also in charge of the energy storage device and load management, and contact and coordination with the large microgrid grid between. Just follow the main 
power output control setting corresponding active and reactive power from the power supply, it does not need to be directly involved in running regulation microgrid. The master-power and communication connections fast and reliable from the structural microgrid from the need to establish between the power source to the main power supply can be adjusted from the operating point to achieve with the micro-grid operation control.

\section{Conclusion}

This paper considers a variety of commonly used in micro-grid distributed power, indepth study based on various control methods and operating distributed power microgrid control strategy and operation mode conversion method, and on this basis. The study based on an inverter-based distribution power control of microgrid power quality management. In this paper, the risk characteristics of grid operations management side under the background of the smart grid, from project investment, load forecasting, renewable energy power purchase access, economic dispatch, information security, were constructed investment project set risk transfer model, load forecasting risk transfer model, considering the economic dispatch model smart grid element of risk transfer.

\section{References}

[1] Q. H. Spencer, A. L. Swindlehurst and M. Haardt, "Zero-Forcing Methods for Downlink Spatial Multiplexing in Multiuser MIMO Channel”, IEEE Transactions on Signal Processing, vol. 52, no. 2, (2004), pp.461-471.

[2] M. Sadek, A. Tarighat and A. H. Sayed, "A Leakage-based Precoding Scheme for Downlink multi-user MIMO Channels", IEEE Transactions on Wireless Communications, vol. 26, no. 8, (2008), pp. 15051515.

[3] J. van de Beek, O. Edfors, M. Sandell, S. Wilson and P. Borjesson, "On Channel Estimation in OFDM System", Proceedings of the IEEE Vehicular Technology Conference, (1995), pp. 815-819.

[4] M. R. Kotecha and A. M. Kothari, "Performance Enhancement of image compression using SVD and Arithmetic Coding", International Journal, vol. 3, (2015).

[5] K. Wong, R. Cheng, K. B. Letaeif and R. D. Murch, "Adaptive antennas at the mobile and base stations in an OFDM/TDMA system", IEEE Transactions on Communications, vol. 49, no.1, (2001), pp. 195206.

[6] M. Sadek, A. Tarighat and A. H. Sayed, "Active Antenna Selection in multi-user MIMO Communications", IEEE Transactions on Signal Processing, vol. 55, no. 4, (2007), pp. 1498-1510.

[7] Y.-Z. Zhu, G.-X. Zheng, Y. Rui and M.-Q. Li, "A Novel Distributed Precoding Scheme Based on THP for Downlink Multi-Cell Multi-User OFDMA Wireless Systems", IJACT: International Journal of Advancements in Computing Technology, vol. 5, no. 9, (2011), pp. 213-220.

[8] E. M. Carlini, G. M. Giannuzzi, P. Mercogliano, P. Schiano, A. Vaccaro and D. Villacci, "A Decentralized and Proactive Architecture based on the Cyber Physical System Paradigm for Smart Transmission Grids Modelling, Monitoring and Control”, Technology and Economics of Smart Grids and Sustainable Energy, vol. 1, no. 1, (2016), pp. 1-15.

[9] D. H. Pham, G. Hunter, L. Li and J. Zhu, "Advanced microgrid power control through grid-connected inverters", In Power and Energy Engineering Conference (APPEEC), IEEE PES Asia-Pacific, IEEE, (2015).

[10] Z. Zhu, J. Tang, S. Lambotharan, W. H. Chin and Z. Fan, "An integer linear programming based optimization for home demand-side management in smart grid", In Innovative Smart Grid Technologies (ISGT), IEEE PES, IEEE, (2012), pp. 1-5.

[11] F. Shariatzadeh, P. Mandal and A. K. Srivastava, "Demand response for sustainable energy systems: A review, application and implementation strategy, Renewable and Sustainable Energy Reviews, vol. 45, (2015), pp. 343-350.

[12] Q. H. Spencer, A. L. Swindlehurst and M. Haardt, "Zero-Forcing Methods for Downlink Spatial Multiplexing in Multiuser MIMO Channel", IEEE Transactions on Signal Processing, vol. 52, no. 2, (2004), pp. 461-471.

[13] M. Sadek, A. Tarighat and A. H. Sayed, "A Leakage-based Precoding Scheme for Downlink multi-user MIMO Channels", IEEE Transactions on Wireless Communications, vol. 26, no. 8, (2008), pp. 15051515.

[14] A. Tarighat, M. Sadek and A. H. Sayed, "A multi User Beamforming Scheme for Downlink MIMO Channels based on Maximizing Signal-to-Leakage Ratios", IEEE International Conference on Acoustics, Speech, and Signal Processing, (2005). 
[15] J. van de Beek, O. Edfors, M. Sandell, S. Wilson and P. Borjesson, "On Channel Estimation in OFDM System", Proceedings of the IEEE Vehicular Technology Conference, (1995).

[16] K. Wong, R. Cheng, K. B. Letaeif and R. D. Murch, "Adaptive antennas at the mobile and base stations in an OFDM/TDMA system", IEEE Transactions on Communications, vol. 49, no.1, (2001), pp. 195206.

[17] M. Sadek, A. Tarighat and A. H. Sayed, "Active Antenna Selection in multi-user MIMO Communications", IEEE Transactions on Signal Processing, vol. 55, no. 4, (2007), pp. 1498-1510.

[18] Y.-Z. Zhu, G.-X. Zheng, R. Yun and M.-L. Li, "A Novel Distributed Precoding Scheme Based on THP for Downlink Multi-Cell Multi-User OFDMA Wireless Systems", IJACT: International Journal of Advancements in Computing Technology, vol. 5, no. 9, (2011), pp. 213-220.

[19] R. Soungalo, R.-F. Li and F.-Z. Zeng, "Evaluating and Improving Wireless Local Area Networks Performance", IJACT: International Journal of Advancements in Computing Technology, vol. 3, no. 2, (2011), pp. 156-164.

[20] L. Tong, G. Xu, B. Hassibi and T. Kailath, "Blind channel estimation based on second-order statistics: a frequency-domain approach”, IEEE Trans. Inform, Theory, vol. 41, (1995), pp. 329-334.

[21] A. M. Bouzid, J. M. Guerrero, A. Cheriti, M. Bouhamida, P. Sicard and M. Benghanem, "A survey on control of electric power distributed generation systems for microgrid applications", Renewable and Sustainable Energy Reviews, vol. 44, (2015), pp. 751-766. 